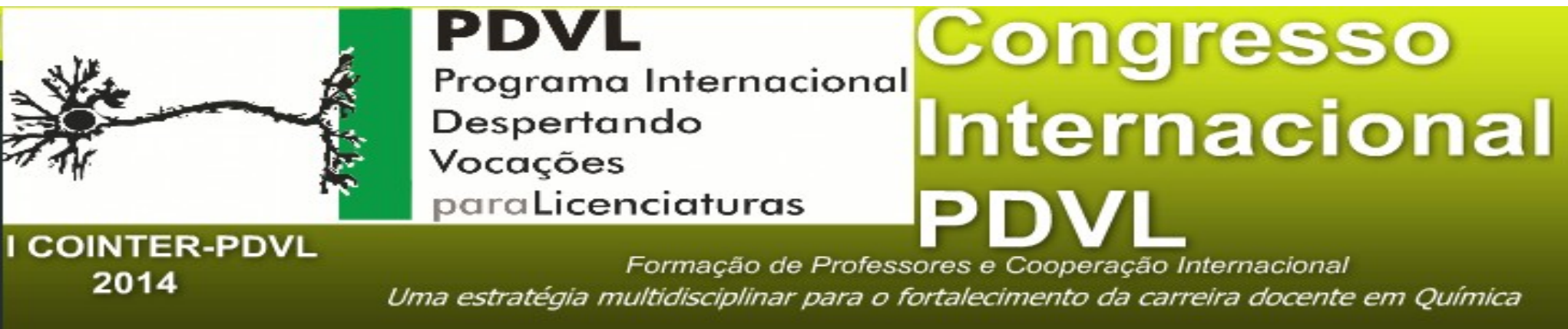

\title{
TECNOLOGIAS EDUCACIONAIS E FORMAÇÃO DE PROFESSORES: OS DESAFIOS DA SALA DE AULA EM TRÊS ESCOLAS DA REGIÃO METROPOLITANA DO RECIFE
}

\author{
Apresentação: Comunicação Oral
}

João Paulo da Silva Santos ${ }^{1}$; Marilene Monteiro Alves da Silva ${ }^{2}$

\section{Resumo}

Este trabalho tem como objetivo investigar como os professores nas mais diversas áreas do conhecimento, de três escolas da Região Metropolitana do Recife, lidam direta ou indiretamente com as tecnologias educacionais em sala de aula em situações didáticas nas suas disciplinas específicas. Em Tardif (2010) encontra-se a existência dos saberes essenciais na formação do professor, que são os saberes docentes inerentes a sua prática pedagógica. Nas salas de aulas com tecnologia educacional é importante entender essa relação que se faz entre o saber do professor e o conhecimento tecnológico. Para tanto, foi aplicado um questionário contendo sete questões com perguntas relativas à importância de recursos didáticos como as tecnologias educacionais, e sua utilização em sala de aula. Os resultados mostraram que os professores já realizaram formação continuada no âmbito das tecnologias educacionais, reconhecem a importância do uso em sala de aula, e também buscam utilizá-las no contexto escolar, alegando que os recursos tecnológicos são aliados importantes no processo de construção do conhecimento.

Palavras-Chave: Tecnologia Educacional. Formação Continuada. Professores.

\section{Introdução}

1 Mestrando em Ensino de Ciências/UFRPE/jpaulo.dssantos@gmail.com 
Em grande parte das escolas, vem acontecendo o fenômeno da presença maciça das tecnologias educacionais em sala de aula. Esse fato deve-se as políticas públicas instituídas pelo governo federal e estadual nas escolas públicas, que visam informatizar e disseminar informações em velocidades cada vez mais rápidas, garantindo assim ao cidadão, uma participação dos debates sociais em tempo real. As salas de aulas deixaram de ser aquele local isolado do resto da comunidade, e os alunos mantém contato com o meio externo quase que instantaneamente através dos celulares, computadores, dos tablets, ou seja, de todo aparato tecnológico que permite aos alunos o acesso a uma gama de informações muitas vezes sem sentido, em curto intervalo de tempo.

Olhando nesse sentido, podemos observar que a sala de aula mudou num ritmo acelerado, deixando várias características de uma escola tradicional para trás. A mudança está presente não só na sala de aula, mas na comunidade onde esse aluno está inserido, trazendo consigo para dentro das escolas, comportamentos sociais que perfazem o estudante da era tecnológica.

Além disso, é importante falarmos como anda a formação do profissional docente, que está imerso num paradigma da modernidade tecnológica que chegou a sala de aula. Esse professor está conectado a sociedade do conhecimento como afirma Valente (1999)? De que forma se encontra esse profissional imerso dentro dessa nova forma de ver o mundo?

Diante dessa problemática, muitos professores afirmam em seus discursos que não estão preparados para lidar com essa nova forma de ver a escola. Dessa forma Lévy (1999) afirma que: "Pela primeira vez na história da humanidade, a maioria das competências adquiridas por uma pessoa no início de seu percurso profissional estarão obsoletas no fim de sua carreira (p. 157)”. Isso mostra quanto ainda à formação do professor é fragmentada e reducionista, não levando em conta essas mudanças que vem acontecendo. Por isso é importante entender, como o professor vê toda essa situação a partir do discurso desses profissionais, e como eles alinham os saberes chamados por Tardif (2010) de saberes profissionais na tentativa de resolver os problemas que estão enfrentando nesse novo paradigma emergente.

\section{Fundamentação Teórica}

Se olharmos a história da informática no Brasil, vamos perceber claramente em alguns autores (TAJRA, 2000; ALMEIDA, 2000) as mudanças que ocorreram no Brasil e no mundo até chegarmos à conjuntura que estamos vivenciando em termos tecnológicos. A introdução 
do computador no Brasil foi decorrente da necessidade de melhorar a segurança nacional, principalmente porque vivíamos um contexto social em que o mundo estava atravessando a Guerra Fria. Na educação, ele chega aos mesmos moldes. Veio para funcionar como uma máquina de ensinar skinneriana (condicionamento operante) que empregava o conceito de instrução programada (ALMEIDA, 2000).

Hoje, temos um aparato tecnológico na escola como nunca visto antes. Temos alunos conectados vinte e quatro horas nas redes sociais em "busca da informação" que lhes interessam. Raras às vezes, essas informações auxiliam na capacidade que esses alunos têm de construir conhecimento, e com isso perdem-se momentos que poderiam ser transformados em espaços permanentes de aprendizagem (MORAN, et al 2000).

Segundo Moran (2000), a sociedade enfrenta ainda uma série de mudanças de paradigmas, onde os modelos tradicionais de ensino não dão conta da gama de situações novas que perfazem o ser social que emerge da escola. E o que preocupa de fato, é que nossos docentes na sua maioria encontram-se sem formação que atenda a nova demanda, por não terem formação inicial e nem continuada no âmbito das tecnologias midiáticas. Não queremos considerar aqui essas novas tecnologias, como soluções para os problemas da educação, mas, entender a importância das mesmas de forma a colaborar no processo de construção do conhecimento.

Sendo assim, como podemos relacionar hoje, o professor com a inovação tecnológica? Segundo Vitalle (1991, p. 6) “O professor não pode delegar a profissionais de informática fornecedores de softwares, programas pedagógicos etc., puramente comerciais - essa escolha de métodos e estratégias”. Cabe, portanto a ele, direcionar as atividades na sala de aula, através de formas e métodos pedagógicos pertinentes, para garantir a construção do conhecimento em nível interdisciplinar. No entanto, falar essas coisas parece uma dialética, pois, de um lado temos a tecnologia em sala de aula e de outro o professor que ainda não está seguro do que fazer com ela.

A formação inicial do professor, ainda contempla modelos tradicionais e com rigor acadêmico que impede que esse profissional, adquira de forma contextualizada os saberes docentes. Estes saberes em nível restrito não constitui a necessidade da escola de hoje. É preciso, portanto, que sejamos capazes de construir conhecimento, não só em nível acadêmico, mas, levando em conta a experiência, as relações sociais estabelecidas pelo aluno.

Segundo Tardif (2010, p.33) “Os professores ocupam uma posição estratégica no 
interior das relações complexas que unem as sociedades contemporâneas aos saberes que elas produzem e mobilizam com diversos fins”. Sendo assim, o professor é essa ponte entre os saberes que são ensinados e a resposta dada pelo aluno na solução dos problemas da sociedade.

Ainda em Tardif (2010), vamos encontrar outros fatores que são importantes nessa discursão, que são os saberes docentes, ou seja, os saberes da formação profissional. Esses saberes orientam a prática do professor na questão disciplinaridade (os saberes disciplinares) como, por exemplo, aqueles que orientam a prática do professor específico de Física e Matemática. Os professores trazem esses saberes, transmitidos pelas instituições de formação de professores.

Os saberes curriculares são aqueles frutos dos programas escolares prontos, bem definidos que os professores devem aprender e colocá-los em prática. E os saberes experienciais são aqueles onde o professor no exercício de sua profissão docente, incorpora determinadas ações individuais, e coletivas frutos da experiência adquirida ao longo do tempo. (Tardif, 2010. p.38).

Hoje, com a gama de novas situações exigidas, pela nova forma de ver o mundo e de construir conhecimento, os professores conseguem aliar estes saberes com o mundo tecnológico? Sem dúvida a formação inicial do professor não dar conta de tanta mudança, e que por isso é necessário à formação continuada. Mas, esta formação deve ser capaz de proporcionar ao profissional docente, métodos e técnicas que possam ser utilizadas no ambiente escolar em situações didáticas. Não basta apenas repetir procedimentos utilizados em contextos tradicionais de ensino. Mas, permitir ao professor, processos de pura reflexão de sua prática (Moran, 2000), que permita ao mesmo, romper o paradigma da escola tradicional desvinculada da sociedade, da comunidade onde o aluno está inserido.

Nesse sentido, as políticas educacionais deveriam dispor de estratégias que permitissem através de formações continuadas, que professores da rede básica de ensino, fossem contemplados com cursos de Atualização, Aperfeiçoamento e Especialização no âmbito das tecnologias educacionais.

\section{Metodologia}

Para a elaboração desse trabalho se fez necessário escolher alguns caminhos sob o ponto de vista metodológico mais apropriado para a pesquisa de campo e investigação de 
como os professores de três escolas da Região Metropolitana do Recife lidam com as tecnologias educacionais.

Segundo Severino (2007) e Merrian (1998) a base inicial de uma pesquisa se dá na diferenciação entre pesquisa qualitativa e quantitativa. A pesquisa de natureza qualitativa tem como principal especificidade, a adequação para identificar a presença ou ausência de determinadas características e fenômenos, ao invés de tentar medir o nível de presença ou de ausência de características em um fenômeno. Busca conhecer o fenômeno sem ater a hipóteses ou teorias previamente formuladas, como ocorre no modelo quantitativo de pesquisa.

Já a pesquisa quantitativa de origem nas ciências naturais, é utilizada em estudos descritivos e nas investigações causais medindo relações de dependência entre variáveis através de dados numéricos. Portanto, a pesquisa realizada tem caráter qualitativo, mas necessitando de dados quantitativos para melhor compreensão.

Foi realizado um estudo de caso, com aplicação de um questionário (ver apêndice C) de forma aberta, tendo os cuidados metodológicos conforme aponta Chagas (2000), a oito professores de escolas localizadas na Região Metropolitana do Recife, sendo duas escolas públicas estaduais do município do Jaboatão dos Guararapes, e uma escola particular do município do Cabo de Santo Agostinho. A faixa etária dos professores da pesquisa está compreendida entre vinte e cinco e cinquenta anos. Estão distribuídos nas mais diversas disciplinas (ver apêndice A).

O critério usado para a escolha do perfil desses profissionais foi à presença dos mesmos nos níveis fundamental um e dois, no ensino médio regular e educação de jovens e adultos (correção de fluxo). É importante mencionar que os professores foram informados sobre a importância da pesquisa, e da publicação das informações obtidas.

Assim, foi realizada uma análise dos dados do questionário levantando o perfil da amostra e os dados foram categorizados e interpretados a luz da teoria.

\section{Resultados e Discussões}

Abaixo, estão descritos os resultados da pesquisa realizada com os professores que responderam o questionário. Inicialmente apresentamos as informações relativas à importância de alguns recursos didáticos midiáticos, bem como o grau de importância dado pelos professores e finalizando com a análise das respostas dadas as questões abertas. 
Estabelecemos no questionário, uma escala de importância relativa aos recursos utilizados em sala de aula. Foi considerado 0 - como não sendo importante, 1 - pouco importante, 2 - importante e 3 - de extrema importância (ver apêndice B).

Pesquisados sobre a importância de alguns recursos didáticos utilizados em sala de aula, percebe-se no apêndice B, cruzando os dados da vertical com a horizontal da tabela, como esses professores veem a utilização desses recursos.

Boa parte deles (mais de 50\%) privilegiam numa escala 2 (importante), os recursos midiáticos como tablet, a internet, revistas e jornais, e a utilização do laboratório de informática como elementos importantes na sala de aula. Essa informação leva-nos a crer, que eles reconhecem a importância desses recursos didáticos que podem contribuir para a dinâmica na sala.

Percebe-se também que, elementos como o livro didático, tem grande impacto nas atividades desses professores (50\% atribuíram escala 3 e 4) levando-nos a crer que é bastante utilizado na sala como recurso didático indispensável.

Outro recurso também citado, em grau de importância foram os experimentos didáticos e as oficinas, (mais de 60\%) citadas numa escala de muito importante. Essa informação mostra que os professores entendem que os alunos precisam alinhar os conteúdos vivenciados em sala de aula, com o contexto em que eles vivem. Outro recurso como a televisão, aparece como pouco importante pela metade deles (50\%) da amostra. Isso evidencia que outros recursos audiovisuais já estão disponíveis na sala de aula que fazem o papel da televisão como Datashow.

No geral percebe-se que o uso de ferramentas ligadas à área tecnológica já é bastante reconhecida por parte desses professores. Será que eles realmente as utilizam?

Já em relação à formação atual atender ou não a demanda da sociedade em nível tecnológico, alguns professores, (quatro deles) em suas falas, citaram que as formações atendem as necessidades da era virtual. Nos discursos é interessante falar que eles percebem essa necessidade. Fica clara essa ideia no discurso de um deles: “O professor, como qualquer outro profissional, precisa se adaptar e se reciclar para atender, também as novas necessidades do mundo tecnológico do século XXI (aprender a usar a internet, tablet, entre outros recursos), mesmo que essas "novidades tecnológicas" não sejam utilizadas todos os dias em sala de aula. Precisa-se despertar para essas novas ferramentas que podem ser grandes aliadas na ministração de qualquer aula /conteúdo /disciplina. Portanto, procuro me renovar, 
aprendendo a utilizar essas ferramentas tecnológicas , mas não abro mão da maior tecnologia, ao meu ver, dentro do âmbito escolar - a boa linguagem - o diálogo na condução de uma boa aula”. (fala do professor 8).

Já a outra metade da amostra, reconhece que está alheia a questão midiática e afirmaram que infelizmente falta política de promoção de formação na área acessível para professores. Outro professor afirmou que: “A formação acadêmica em licenciatura não dá tanto suporte as questões tecnológicas. São realizados cursos de capacitação a parte, mas estes não estão atendendo a demanda exigida”. (fala do professor 1).

Outra abordagem foi em relação à visão que os profissionais docentes têm em relação à inserção das tecnologias midiáticas em sala de aula, e se elas contribuem para o aprendizado dos alunos. Mais da metade da amostra considera que as tecnologias midiáticas contribuem para o aprendizado do aluno. E que elas hoje, podem se tornar um grande aliado do professor no processo de construção de conhecimento. Fica clara essa posição quando um deles afirma que: “Atualmente a inserção dessas tecnologias em sala de aula tornou-se um recurso quase que indispensável devido ao acesso fácil que os alunos têm da mesma, fora da escola. Só o discurso do professor parece ficar meio perdido em um espaço onde é indispensável que os estudantes prendam sua atenção”. (...) (fala do professor 6).

Outro professor (professor 4) afirmou que é relativo, e alegou que se tecnologia midiática contribui ou não, vai depender do público alvo, ou seja, da comunidade, dos alunos, do interesse e motivação de cada um deles.

Em relação à política pública de formação do governo, relativa à formação continuada para a inserção das mídias em sala de aula, todos eles relataram que ainda é incipiente e infelizmente essas políticas ainda é muito fragmentada e apenas visa à promoção partidária. “Deveria haver a escuta dos profissionais docentes na elaboração dessas políticas” (...). (fala do professor 7 ).

Outra problemática levantada consiste em saber como o professor se sente em ter que lidar com o uso das novas tecnologias e quais os caminhos que os mesmos apontariam para melhorar sua prática pedagógica. Seis professores apontaram que ainda não se encontram preparados para lidar com tanta informação e que os caminhos necessários para alcançar um desempenho melhor, seriam as formações continuadas e cursos de atualização. Um professor afirmou que: “não é só a questão de está atualizado ou não, mas sim, traçar técnicas que 
despertem a curiosidade, a imaginação e o pensamento crítico do aluno e usar as tecnologias midiáticas quando realmente for necessário”. (fala do professor 8).

Foi pedido também, que cada professor relatasse sua experiência em ter participado de formações para o uso de recursos midiáticos, caso tenha participado. Da amostra, seis professores relataram ter participado, mas que não basta ficar apenas na teoria. "É preciso colocar o que aprendemos em prática desde que tenhamos material em mãos para trabalharmos” (...) (fala do professor 2). Outros citaram que às vezes as formações acontecem e infelizmente não saem do discurso pedagógico por falta de material na sala de aula. Essa ideia fica evidente no discurso de um professor quando afirma que: “(...) a diferença e disparidade entre a teoria (formação) e a prática (sala de aula) são enormes (...) participei de uma formação tecnológica excelente, e enfrento uma realidade oposta em sala de aula (Datashow ultrapassado para leitura das novas configurações de arquivos e programas da internet; televisores e aparelhos de DVDs também ultrapassados e também a falta ou inexistência de acesso à internet fornecida pela própria escola”. (fala do professor 8).

Foi questionado com intuito de saber a opinião dos profissionais docentes, sobre o que eles pensam sobre uma alfabetização científica tecnológica para todos os cidadãos e se isso poderia contribuir para resolver os problemas da sociedade. Os professores em sua maioria (cinco deles) acreditam que hoje em pleno o século XXI é importante que todos os cidadãos, tenham conhecimentos básicos para exercerem a cidadania de forma livre e consciente.

Alguns relataram também a importância no uso de aparelhos tecnológicos no dia-a-dia como caixa eletrônico, urnas eletrônicas para votação nas eleições para representantes de governo que já fazem parte do nosso cotidiano há anos. Outros (dois) acreditam em parte que, alfabetizar cientificamente a população, pode diminuir muitos dos problemas que enfrentamos, pois muitos deles dependem de uma complexidade e não apenas de alfabetizar a população cientificamente. Segundo Cachapuz (2011) a participação da população principalmente nas decisões que envolvem o conhecimento científico é imprescindível principalmente quando envolvem questões desenvolvimento que incorre em riscos ao meio ambiente.

Portanto, fica claro na fala da maioria dos professores, que essa alfabetização pode garantir ao cidadão um poder de decisão mais eficaz na sociedade no sentido de garantir um discurso consistente e bem fundamentado no momento de decidir em coletivo. 


\section{Conclusões}

A partir dos dados analisados, percebe-se que os professores reconhecem a importância das tecnologias educacionais no processo educacional, e sentem - se motivados a trabalhar com elas. No entanto, a formação inicial não contempla as habilidades necessárias para atender à demanda da sociedade atual, e que por isso, muitos ainda não estão totalmente seguros em utilizá-las em sala de aula.

É preciso fortalecer e criar novas políticas que priorize a formação dos professores no âmbito tecnológico. Essas políticas devem contemplar formações continuadas, cursos de Especializações priorizando o momento e o contexto social que estamos vivendo, no sentido de desmistificar o medo que alguns profissionais sentem em lhe dar com o novo. Vale lembrar que a escola está situada numa comunidade com necessidades próprias, que é produto da interação entres sujeitos que ali residem e que, portanto, precisam solucionar os problemas coletivos e individuais que emergem da sociedade. Os dados da pesquisa mostram claramente esse problema nas escolas pesquisadas e não está distante da realidade de muitas outras escolas públicas e particulares.

Os professores necessitam claramente incorporar aos seus saberes docentes os saberes tecnológicos, que orientarão suas práticas pedagógicas em sala de aula. Dessa forma os paradigmas da escola tradicional poderão ser revistos, a escola deixará de ser apenas uma mera transmissora de informações para ser agregadora de valores ajudando os alunos a construírem conhecimento numa perspectiva emancipadora.

\section{Referências}

ALMEIDA, M. E; ProInfo: Informática e Formação de Professores. Vol. 1; Brasília: MEC/ Secretaria de Educação à Distância -, 2000; 192 p.

CACHAPUZ, A. et al. (organizadores). A Necessária renovação do ensino das ciências. São Paulo: Cortez, 2005.

CARVAlHO, A.M.P. (ORG). Ensino de Ciências: Unindo a Pesquisa e a Prática. São Paulo: Pioneira Thomson Learning, 2004. 
CHAGAS, A.T.R. O questionário na pesquisa científica. Revista de Administração [online].Volume1 , nº 1 São Paulo: SP, janeiro 2000. Disponível na internet: www.fecap.br/adm_online/adol/artigo.htm.

LEVY, P. Cibercultura. São Paulo: Editora 34, 1999.

MERRIAM, S.What is qualitative research? In: . Quallitative research and case study applications in education. San Francisco: Jossey - Bass, 1998.

MORAN, J. M; MASETTO, M. T.; BEHRENS, M. A. Novas tecnologias e mediação pedagógica. Campinas: Papirus, 2000.

SEVERINO, Antônio J. Metodologia do trabalho científico. 23ed. São Paulo: Cortez, 2007.

TAJRA, S. F. Informática na Educação: Novas Ferramentas Pedagógicas para o Professor da Atualidade. São Paulo: Érica, 2000.

TARDIF, M. Saberes docentes e formação profissional, 11ª edição. Petrópolis, RJ: Vozes, 2010.

VALENTE, J. A.(org). O computador na sociedade do conhecimento. Campinas, SP:UNICAMP/NIED, 1999.

VITALLE, B. Computador na escola: um brinquedo a mais? Ciência Hoje, Rio de Janeiro: v.13, no77, p.18-25, 1991.

\section{Apêndice A}

Quadro 1 - Perfil dos professores da pesquisa. Fonte: própria

\begin{tabular}{|c|c|c|c|}
\hline $\begin{array}{c}\text { Profess } \\
\text { or }\end{array}$ & Formação acadêmica & Disciplina(s) que leciona & $\begin{array}{c}\text { Turmas onde } \\
\text { leciona }\end{array}$ \\
\hline 1 & $\begin{array}{l}\text { Ciências Exatas e Naturais - } \\
\text { Habilitação : Matemática }\end{array}$ & Matemática & $8^{\circ}$ e $9^{\circ}$ anos \\
\hline 2 & Pedagogia & $\begin{array}{l}\text { Polivalente (Português, } \\
\text { Matemática, ciências,...) }\end{array}$ & $\begin{array}{c}2^{\circ} \text { ano do } \\
\text { fundamental } 1\end{array}$ \\
\hline 3 & $\begin{array}{l}\text { Licenciatura Plena em } \\
\text { Geografia e Economia } \\
\text { Doméstica }\end{array}$ & (Geografia, História) & $\begin{array}{c}\text { Projeto Travessia } \\
\text { médio - Correção } \\
\text { de fluxo }\end{array}$ \\
\hline 4 & Licenciatura Pena em História & História & $6^{\circ}$ e $7^{\circ}$ anos \\
\hline 5 & Pedagogia & $\begin{array}{l}\text { Polivalente (Português, } \\
\text { Matemática, ciências,...) }\end{array}$ & $\begin{array}{c}3^{\circ} \text { ano }- \\
\text { Fundamental } 1\end{array}$ \\
\hline 6 & $\begin{array}{c}\text { Licenciatura Plena em } \\
\text { Pedagogia } \\
\text { Especialização em Gestão da } \\
\text { Educação e Políticas da } \\
\text { Juventude } \\
\end{array}$ & Filosofia, Música, Artes & $\begin{array}{l}\text { Projeto Travessia } \\
\text { médio - Correção } \\
\text { de fluxo }\end{array}$ \\
\hline 7 & Administração & Matemática & $1^{\circ}$ e $3^{\circ}$ anos do \\
\hline
\end{tabular}




\begin{tabular}{c|l|c|c}
\hline & & & ensino médio \\
\hline 8 & Licenciatura Plena em História & $\begin{array}{c}\text { História, Filosofia e } \\
\text { Sociologia }\end{array}$ & $\begin{array}{c}1^{\circ}, 2^{\circ} \text { e } 3^{\circ} \text { anos do } \\
\text { Ensino médio }\end{array}$ \\
\hline
\end{tabular}

\section{Apêndice B}

Tabela 1 - Grau de importância dos recursos utilizados em sala de aula. Fonte: própria

\begin{tabular}{c|c|c|c|c|}
\hline \multirow{2}{*}{ RECURSO } & \multicolumn{4}{|c}{ ESCALA DE IMPORTÂNCIA } \\
\cline { 2 - 5 } DIDÁTICO & 0 & 1 & 2 & 3 \\
\hline Tablet & 1 & & 6 & 1 \\
\hline Livro didático & & & 4 & 4 \\
\hline Datashow & & 1 & 4 & 3 \\
\hline Televisão & & 4 & 3 & 1 \\
\hline Experimentos didáticos & & & 2 & 6 \\
\hline Robótica educativa & & 1 & 4 & 2 \\
\hline Internet & & & 6 & 2 \\
\hline Revistas e jornais & & & 5 & 3 \\
\hline $\begin{array}{c}\text { Laboratório de } \\
\text { informática }\end{array}$ & & 1 & 5 & 2 \\
\hline Oficinas & \multicolumn{3}{|c}{3} \\
\hline
\end{tabular}

Apêndice C

Questionário de pesquisa

\begin{tabular}{|l|l|}
\hline Formação acadêmica & \\
\hline $\begin{array}{l}\text { Disciplina (s) que } \\
\text { leciona }\end{array}$ & \\
\hline Turmas que leciona & \\
\hline
\end{tabular}

. Considere a seguinte escala de importância sobre os seguintes instrumentos em sala de aula:

$$
0 \text { - Não é importante } \quad 1 \text { - pouco importante } \quad 2 \text { - importante } \quad 3 \text { - muito importante }
$$

\begin{tabular}{|l|l|l|l|}
\hline 1.1. tablet & 1.2. Robótica educativa & \\
\hline 1.3. Livro didático & & 1.4 . Internet & \\
\hline 1.5. Datashow & & 1.6. Revistas e jornais & \\
\hline $\begin{array}{l}\text { 1.7. Televisão } \\
\text { 1.9. Experimentos } \\
\text { didáticos }\end{array}$ & $\begin{array}{l}\text { 1.8. laboratório de } \\
\text { Informática }\end{array}$ & \\
\hline
\end{tabular}

2- Você acha que a sua formação atual atende a demanda exigida pela sociedade em nível tecnológico? 
3 - Qual a sua visão em relação à inserção de tecnologias midiáticas em sala de aula? Elas contribuem para o aprendizado dos alunos?

4 - Em relação à política de governo, como você avalia a formação recebida pelo professor para a inserção de novas tecnologias em sala de aula? Ela é adequada?

5 - Você sente-se preparado para lidar com tanta informação advinda do uso das novas tecnologias em sala de aula? Que caminhos você apontaria para melhorar sua prática pedagógica?

6 - Você já participou de alguma formação tecnológica para o uso de materiais midiáticos em sala de aula? Ela(s) atendeu (ram) as suas expectativas? Relate a experiência.

7 - O que você acha da alfabetização científica para todos os cidadãos em nível tecnológico? Ela pode contribuir para solução de problemas em sociedade? 